\title{
Imprescriptibilidad vs impunidad en la transición española
}

\author{
Imprescriptibility vs Impunity In The Spanish Transition
}

Recibido: 22-04-2018 • Aprobado: 01-06-2018 • Página inicial: 233 - Página final: 249

\author{
Roque Moreno Fonseret* \\ Virgilio Francisco Candela**
}

\begin{abstract}
Resumen: en este artículo se analiza la situación actual existente en España respecto de la justicia y la reparación de las víctimas del franquismo, cuarenta y tres años después de la muerte de Francisco Franco. La represión del Estado autoritario propició más de 30.000 desaparecidos que todavía hoy, pese a una Ley de Amnistía que data de 1977, y de una Ley de Memoria Histórica creada en 2007, no han sido juzgados los responsables, ni reparada su memoria. Es este un análisis de la impunidad existente en España donde se constata que no solo no se ha atendido a las víctimas de crímenes de derecho internacional cometidos durante la Guerra Civil y el franquismo en territorio peninsular, sino que, incluso, en muchas oportunidades se ha impedido el acceso a la justicia a las familias de las víctimas. Se concluye la investigación advirtiendo que sin justicia ni reparación no es posible la reconciliación nacional.
\end{abstract}

Palabras clave: franquismo, represión, Estado, impunidad, víctimas.

\begin{abstract}
This article analyses the current situation in Spain concerning the justice and the reparation of the victims of Francoism forty-three years after the death of Francisco Franco. The repression of the authoritarian State caused more than 30.000 missing that still today, in spite of the Amnesty Law of 1977, and the Historical Memory Law created in 2007, have not been tried or repaired the victims' memory. We suggest an exhaustive analysis of the existent impunity in Spain where international crimes committed during the Civil War and the Franco regime has not been attended, but even, in a lot of opportunities, has been disabled the access to the victims' families. It concludes the investigation warning that without justice reparation it is not possible the national reconciliation.
\end{abstract}

Keywords: Francoism, repression, State, impunity, victims.

\footnotetext{
* Catedrático de Historia Contemporánea de la Universidad de Alicante - España. Coordinador del Área de Didáctica de las Ciencias Sociales de la Facultad de Educación. Director del Instituto Universitario de Estudios Sociales de América Latina (IUESAL) de la misma universidad. roque.moreno@ua.es.

Enlace ORCID: https://orcid.org/0000-0003-2162-0295

** Profesor de Didáctica de la Historia en la Facultad de Educación de la Universidad de Alicante - España. Doctorando en Ciencia Política y de la Administración de la misma universidad.

virgilio.candela@ua.es.

Enlace ORCID https://orcid.org/0000-0001-9877-9160
} 


\title{
Imprescriptibilité vs impunité dans la transition espagnole
}

\begin{abstract}
Résumé: cet article analyse la situation actuelle en Espagne en matière de justice et de réparation pour les victimes du régime franquiste, quarante-trois ans après la mort de Francisco Franco. La répression de l'État autoritaire a entraîné la disparition de plus de 30.000 personnes qui, même aujourd'hui, malgré une loi d'amnistie datant de 1977 et une loi sur la mémoire historique créée en 2007, n'ont pas été jugées ni réparées. Il s'agit d'une analyse de l'impunité qui existe en Espagne où il est noté que non seulement les victimes de crimes de droit international commis pendant la guerre civile et Franco n'ont pas été desservies, mais que, dans de nombreux cas, elles ont été victimes de crimes. empêché l'accès à la justice pour les familles des victimes. L'enquête est terminée, avertissant que sans justice ni réparation, la réconciliation nationale n'est pas possible.
\end{abstract}

Mots-clés: franquisme, répression, État, impunité, victimes.

\section{Impescriptibilidade vs impunidade na transição espanhola}

Resumo: este artigo analisa a situação atual na Espanha em relação à justiça e reparação para as vítimas do regime de Franco, quarenta e três anos após a morte de Francisco Franco. A repressão do estado autoritário levou a mais de 30.000 desaparecidos que, ainda hoje, apesar da Lei de Anistia de 1977 e da Lei de Memória Histórica criada em 2007, não foram julgados ou reparados em sua memória. Esta é uma análise da impunidade existente na Espanha, onde se observa que não só não foram atendidas vítimas de crimes de direito internacional cometidos durante a Guerra Civil e Franco em território continental, mas mesmo, em muitos casos, tem sido impediu o acesso à justiça para as famílias das vítimas. Conclui-se a investigação alertando que, sem justiça ou reparação, a reconciliação nacional não é possível.

Palavras-chave: franquismo, repressão, Estado, impunidade, vítimas. 


\section{La represión franquista y los “desaparecidos” en España}

Durante la misma guerra civil y hasta prácticamente la muerte del dictador en 1975, el régimen franquista fue configurando un régimen represor que tenía como objetivo último la persecución de todos los que fueran considerados desafectos a éste. La represión fue amplia, sistemática, y no sólo contempló la reclusión y eliminación del enemigo sino también todo tipo de sanciones económicas e incautación de bienes, depuraciones administrativas, destierros o sanciones morales. Esta represión pudo llevarse a cabo gracias a la rápida construcción de todo un entramado institucional en el que destacaron organismos o leyes creadas ex profeso para castigar al enemigo como los Consejos Guerra, la Ley de Depuración de Empleados Públicos, las Juntas de Incautación de Bienes, el Tribunal Especial contra la Masonería y el Comunismo, los Tribunales de Responsabilidades Políticas y, a partir de 1963, el Tribunal de Orden Público (Sánchez-Recio, 2016). Esta forma de represión es la que se ajustaba materialmente al Código de Justicia Militar de 1890; comenzó a aplicarse durante la guerra civil en la zona franquista a medida que iban controlando la retaguardia y se generalizó al final de la misma en la zona que se mantuvo leal a la República. Es necesario destacar que esta represión se prolongó hasta la muerte del dictador; si bien con el transcurso del tiempo fue adoptando métodos no tan masivos que se fueron ajustando a la "legalidad" del sistema judicial franquista.

La represión física presentó además otra forma: aquella que fue ejecutada de manera directa, arbitraria e indiscriminada, pero con el conocimiento y la aceptación de los jefes militares, para limpiar la retaguardia de todas las personas que consideraban enemigas. Buenos ejemplos de esta forma de represión son las ejecuciones cometidas en Galicia, Castilla León y Canarias, así como las realizadas por el ejército en su avance hacia Madrid en las provincias de Huelva y Badajoz. Este tipo de represión se aplicó durante la guerra civil y los días que duró el desconcierto al final de la misma.

El balance de ambas formas de represión es aterrador, hasta el punto que se ha llegado a hablar de holocausto para referirse a las dimensiones de la violencia franquista. Paul Preston señaló en 2011 que a su juicio debe hablarse de holocausto dado el alto número de víctimas y las características de la represión. Según las estimaciones compiladas por dicho autor, durante la guerra civil española cerca de 200.000 hombres y mujeres fueron asesinados lejos del frente, ejecutados extrajudicialmente o tras precarios procesos legales, y al menos 300.000 hombres perdieron la vida en los frentes de batalla. Además, un número 


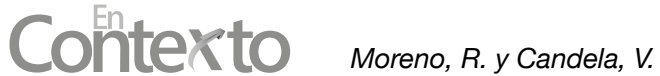

desconocido de hombres, mujeres y niños fueron víctimas de los bombardeos y los éxodos que siguieron a la ocupación del territorio por parte de las fuerzas militares de Franco. Señala también dicho autor que tras la victoria definitiva de los rebeldes a finales de marzo de 1939, alrededor de 20.000 republicanos fueron ejecutados; muchos más murieron de hambre y enfermedades en las prisiones y en los campos de concentración donde se hacinaban en condiciones infrahumanas; otros sucumbieron a las condiciones esclavistas de los batallones de trabajo y a más de medio millón de refugiados no les quedó otra salida que el exilio; muchos perecieron en los campos de internamiento franceses. Varios miles acabaron en los campos de exterminio nazis (Preston, 2011).

No obstante, probablemente el término que mejor defina la represión franquista, por estar más libre de connotaciones raciales o religiosas, sea el de exterminio, por su significado de aniquilar o extirpar de diversas formas a los que se habían mantenido leales o habían colaborado con la República, no excluyendo de la aniquilación, la persecución o la marginación social a nadie, perteneciera al grupo de edad que fuera (Sánchez-Recio, 2012). De esta manera, el exterminio no sólo supondría la destrucción física del enemigo sino también de la cultura democrática republicana como hemos expuesto en anteriores trabajos (SánchezRecio, 2016). Michael Richards redunda en esta idea y advierte a su vez de los límites del método cuantitativo en el estudio de la historia de la represión en el régimen franquista, cuando los problemas de la cronología, de la localización, de la legalidad y de la reconstrucción histórica no se tratan de forma sistemática. La utilización del concepto "exterminio" tiene un significado tanto cualitativo como cuantitativo, y puede ser aplicado, en el caso español, a la destrucción total de una cultura democrática, así como a la destrucción física entre los grupos sociales, representantes principales de la modernidad (Richards, 2007).

La mayoría de las 100.000 personas que se llevó a la tumba la violencia franquista durante la guerra y de las 50.000 que fueron ejecutadas en los 10 años que siguieron al final de la guerra, están identificadas y constan en los registros civiles de cientos de localidades. Existen otros miles de víctimas a las que nunca se registró, abandonadas por sus asesinos en las cunetas de las carreteras, en las tapias de los cementerios, en los ríos, en pozos y minas, o enterradas en fosas comunes. Su número, según señala Julián Casanova, puede llegar, como mucho, a 30.000 en toda España, paseados casi todos en los primeros meses de la guerra, en el verano y otoño de 1936, o en las semanas que seguían a la ocupación de las diferentes ciudades por las tropas franquistas (Casanova, 2008). Todavía hoy en día, buena parte de estos "desaparecidos" continúan allí, a la espera de que una parte de la sociedad española consiga 
entender que la dignificación de estas víctimas debe ser irrenunciable si se quiere realmente cerrar las heridas. Así las cosas, en la actualidad, el debate sobre nuestro pasado más reciente se desarrolla en torno a dos cuestiones: la ley de la memoria histórica, aprobada a finales de 2007, y la referente a los desaparecidos o, lo que es lo mismo, los derechos imprescriptibles de las víctimas, que se planteó inmediatamente después, al constatar que dicha ley no respondía a las demandas de las Asociaciones para la Recuperación de la Memoria Histórica y de los familiares de las víctimas (Sánchez-Recio, 2018).

\section{Las leyes de amnistía en la transición española}

Los actores de la transición española ignoraron el debate y se prestaron raudos a correr un tupido velo sobre lo acontecido en la dictadura, de ahí que las tensiones (y las heridas) mencionadas sigan abiertas casi cuarenta años después. Los treinta años transcurridos entre la Ley de Amnistía de 1977 y la de Memoria Histórica de 2007 así lo revelan.

El análisis de la impunidad en España debemos datarlo en la promulgación de la Ley de Amnistía (Ley 46, 1977) el 15 de octubre de 1977, la primera gran medida aprobada por las nuevas Cortes tras la celebración de elecciones democráticas el 15 de junio de ese mismo año. Previamente, se aprobaron dos amnistías parciales como precedentes inmediatos de la Ley 46 en la predemocracia española surgida tras la muerte del dictador.

Efectivamente, en julio de 1976, días después del nombramiento de Adolfo Suárez ${ }^{1}$ como presidente del Gobierno por el monarca borbón Juan Carlos I, ${ }^{2}$ se aprobó una amnistía parcial (Real Decreto-Ley 10, 1977) que afectó a presos por motivación política o de opinión y a los relacionados con la sedición militar. Destacados dirigentes comunistas ${ }^{3}$ y miembros de la $\mathrm{UMD}^{4}$ fueron excarcelados por la medida de gracia pero no así los presos vascos condenados por terrorismo al haber cometido delitos de sangre. El Decreto-Ley de 30 de julio de 1976 señalaba la voluntad de la Corona de:

\footnotetext{
E1 5 de julio de 1976 .

Recordemos que era potestad del jefe del Estado heredado del franquismo elegir al presidente del Gobierno entre una terna de candidatos presentada por el Consejo del Reino.

3 Gracias a la primera amnistía del gobierno de Adolfo Suárez pudieron salir de la cárcel tres dirigentes comunistas históricos como Simón Sánchez Montero, Santiago Álvarez y José Unanue.

4 La Unión Militar Democrática fue una organización militar clandestina que surgió en 1974 con el objetivo de democratizar las Fuerzas Armadas y propiciar la democracia en España. En 1976 fueron detenidos sus líderes organizativos y condenados a penas de cárcel e incluso a la expulsión del Ejército.
} 
(...) promover la reconciliación de todos los miembros de la Nación (...) Tal es el caso de la reintegración de los derechos pasivos a los militares sancionados después de la pasada contienda, de los distintos indultos concedidos y de la prescripción, por ministerio de la ley, de todas las responsabilidades penales por hechos anteriores al 1 de abril de 1939 (Real Decreto-Ley 10, 1977).

La medida de gracia adoptada por el presidente Suárez y el rey Juan Carlos I, pretendió inaugurar una nueva etapa de cariz reformista en España para apaciguar los ánimos de una sociedad española que clamaba "amnistía y libertad" en todas las manifestaciones públicas de ese complejo año de 1976. Es preciso recordar que diariamente se producían en el territorio nacional movilizaciones de signo político, laboral y económico propiciadas por una oposición antifranquista que trataba de presionar al Gobierno para acelerar la llegada de la democracia a nuestro país.

Si bien esta primera amnistía fue recibida favorablemente por la opinión pública española, lo cierto es que no ocurrió lo mismo en el País Vasco. La inestabilidad política y la presión de la banda terrorista E.T.A. ${ }^{5}$ en forma de atentados, propició la aprobación unos meses después de otros dos decretosley ${ }^{6}$ de ampliación de la amnistía que esta vez se extendió a los presos vascos acusados de terrorismo pero sin delitos de sangre, con el intercambio de cárcel por extrañamientos (Santos, 2008). Era preciso construir un escenario propicio para afrontar las elecciones del 15 de junio que habían sido convocadas tras la aprobación de la Ley de Reforma Política, de noviembre de $1976 .{ }^{7}$ En las elecciones resultó vencedor el partido del presidente Suárez, la Unión de Centro Democrático (UCD), aunque sin alcanzar la mayoría absoluta, y se erigió en principal partido de la oposición el Partido Socialista Obrero Español (PSOE).

Tras la cita electoral, las nuevas Cortes constituyentes procedieron a debatir y a aprobar la Ley de Amnistía al inicio de su labor legislativa. Fue una Ley respaldada por la práctica totalidad de los grupos parlamentarios: se obtuvieron 296 votos a favor, 2 en contra, 18 abstenciones y un voto nulo. Los principales partidos políticos democráticos votaron a favor de la amnistía: Unión de Centro

5 Euskadi Ta Askatasuna (ETA, País Vasco y Libertad) fue un grupo terrorista vasco autodefinido como independentista, abertzale, socialista y revolucionario, escisión del Partido Nacionalista Vasco, y que tuvo una importante actividad terrorista en la pre democracia española.

6 Fueron el Decreto-Ley 19/1977, de 14 de marzo, sobre medidas de gracia y el Decreto 388/1977 y también de 14 de marzo, sobre indulto general.

7 El propio historiador Santos Juliá explica en este trabajo cómo la Comisión de los Nueve en reunión con el presidente del Gobierno celebrada el 11 de enero de 1977, ya reclamó que se otorgara una amnistía de todos los hechos y delitos de intencionalidad política ocurridos entre el 18 de julio de 1936 y el 15 de diciembre de 1976. Aquella Comisión estuvo integrada, entre otros, por Felipe González, Antón Canyellas, Julio Jáuregui y Joaquín Satrústegui. 
Democrático, Partido Socialista Obrero Español, Partido Socialista Popular, Partido Comunista de España, la Minoría Vasco-Catalana y el Grupo Mixto. La formación conservadora y nostálgica del franquismo, Alianza Popular, se abstuvo en aquella ocasión. Los dos primeros artículos de la Ley de Amnistía resumían el espíritu de aquella norma legislativa:

\section{Artículo primero}

I. Quedan amnistiados:

a) Todos los actos de intencionalidad política, cualquiera que fuese su resultado, tipificados como delitos y faltas realizados con anterioridad al día quince de diciembre de mil novecientos setenta y seis.

b) Todos los actos de la misma naturaleza realizados entre el quince de diciembre de mil novecientos setenta y seis y el quince de junio de mil novecientos setenta y siete, cuando en la intencionalidad política se aprecie además un móvil de restablecimiento de las libertades públicas o de reivindicación de autonomías de los pueblos de España.

c) Todos los actos de idéntica naturaleza e intencionalidad a los contemplados en el párrafo anterior realizados hasta el seis de octubre de mil novecientos setenta y siete, siempre que no hayan supuesto violencia grave contra la vida o la integridad de las personas.

II. A. Los meros efectos de subsunción en cada uno de los párrafos del apartado anterior, se entenderá por momento de realización del acto aquel en que se inició la actividad criminal.

La amnistía también comprenderá los delitos y faltas conexos con los del apartado anterior.

\section{Artículo segundo}

En todo caso están comprendidos en la amnistía:

a) Los delitos de rebelión y sedición, así como los delitos y faltas cometidos con ocasión o motivo de ellos, tipificados en el Código de justicia Militar.

b) La objeción de conciencia a la prestación del servicio militar, por motivos éticos o religiosos.

c) Los delitos de denegación de auxilio a la Justicia por la negativa a revelar hechos de naturaleza política, conocidos en el ejercicio profesional. 
d) Los actos de expresión de opinión, realizados a través de prensa, imprenta o cualquier otro medio de comunicación.

e) Los delitos y faltas que pudieran haber cometido las autoridades, funcionarios y agentes del orden público, con motivo u ocasión de la investigación y persecución de los actos incluidos en esta Ley.

f) Los delitos cometidos por los funcionarios y agentes del orden público contra el ejercicio de los derechos de las personas (Ley 46, 1977).

A grandes rasgos la Ley de Amnistía aprobada por el Parlamento Español indultaba todos los delitos "de motivación política" desarrollados en la transición (incluyendo los actos terroristas con víctimas mortales); también los crímenes cometidos por los grupos radicales de ultraderecha del postfranquismo, así como todos los delitos cometidos en España desde el inicio de la Guerra Civil y durante la dictadura, incluyendo la represión y la depuración franquista.

Un "pacto de silencio" (Reig-Tapia, 1984) entre las formaciones políticas de izquierda y derecha; o una "autoamnistía" como así planteó Francisco Espinosa (2007); o una ley de punto final. Sea como fuere, lo cierto es que aquella Ley de consenso político significó una apelación a la amnesia colectiva institucional para favorecer el éxito de un proceso de transición hacia la democracia en la convulsa España del postfranquismo. Efectivamente, casi sin excepción, los partidos políticos españoles de 1977 renunciaron a revisar el pasado y a exigir las oportunas responsabilidades, ocasionadas durante los cerca de cuarenta años que duró la cruenta e implacable dictadura de Francisco Franco, y su consiguiente etapa de transición. Incluso aquellos que más sufrieron la represión franquista a lo largo de los años, como fue el caso de comunistas y socialistas.

\section{España, al margen del Derecho Internacional}

España aprobó una Ley de Amnistía pese a haber ratificado en abril de ese mismo año el Pacto Internacional de Derechos Civiles y Politicos ${ }^{8}$ de Naciones Unidas, un compromiso para poder juzgar y condenar hechos delictivos que tuvieran carácter internacional en el seno de un Estado, pese a no ser considerado como tal según el derecho nacional en el momento en el que se cometieron.

La Ley patria inutilizó este principio. También España firmó el 4 de octubre de 1979 el Convenio Europeo para la Protección de Derechos Humanos y de las Libertades Fundamentales. ${ }^{9}$ En su articulado se explicitaba lo siguiente:

8 Suscrito por España y publicado en el B.O.E. el 30 de abril de 1977.

9 Fue firmado en 1950 en Roma por el Consejo de Europa. 
El presente artículo no impedirá el juicio y el castigo de una persona culpable de una acción o de una omisión que, en el momento de su comisión, constituía delito según los principios generales del derecho reconocidos por las naciones civilizadas (BOE, Art. 7.2, Núm. 243, 1979).

De otra parte, el Estatuto de Roma de la Corte Penal Internacional, ${ }^{10}$ firmado en 1998 y ratificado por nuestro país, ${ }^{11}$ establecía ya en su preámbulo que los delitos de lesa humanidad no podían quedar impunes. Se afirmaba en el texto que los crímenes más graves de trascendencia para la comunidad internacional no debían quedar sin castigo, siendo deber de todo Estado ejercer su jurisdicción penal contra los responsables de crímenes internacionales.

Pese a todo, a lo largo de los últimos cuarenta años, ningún gobierno español ha desarrollado ninguna política pública destinada a reparar a las víctimas de crímenes de derecho internacional cometidos durante la Guerra Civil y el franquismo en territorio peninsular. Incluso podemos ir más allá afirmando que en muchas ocasiones se ha impedido u obstaculizado el acceso a la justicia y a la reparación a las familias de las víctimas.

Prueba de nuestra categórica afirmación la encontramos en los diferentes episodios judiciales que exponemos a continuación, y muy a pesar de las diferentes acusaciones de organismos internacionales jalonadas a lo largo de los años. Comenzaremos con las denuncias presentadas en julio de 2007 por parte de varias asociaciones de derechos humanos ante la Audiencia Nacional para la investigación de los crímenes del franquismo. Fueron finalmente desestimadas puesto que los delitos habían prescrito o estaban sujetos a la Ley de Amnistía de 1977.

Previo a todo ello es pertinente reseñar que en el año 2007 se aprobó en España la conocida Ley de Memoria Histórica (Ley 52, 2007) durante el mandato de José Luis Rodríguez Zapatero como presidente del gobierno. Un texto que incluía el reconocimiento de todas las víctimas de la Guerra Civil y de la dictadura del general Francisco Franco, pero no así la apertura de fosas comunes en las que aún yacen los restos de represaliados por los sublevados, que quedaba desde la Ley reducida al ámbito privado (personal y familiar). ${ }^{12}$ En la actualidad, bajo el

10 Aprobado en Roma (Italia) el 17 de julio de 1998 por la Conferencia Diplomática de Plenipotenciarios de las Naciones Unidas sobre el establecimiento de una Corte Penal Internacional.

11 Instrumento de Ratificación del Estatuto de Roma de la Corte Penal Internacional, hecho en Roma el 17 de julio de 1998 (Boletín Oficial del Estado núm. 126, de 27 de mayo de 2002).

12 Diferentes entidades privadas como la Asociación para la Recuperación de la Memoria Histórica (ARMH) y el Foro por la Memoria han denunciado que los delitos del franquismo son cometidos contra la sociedad y la humanidad y por tanto es deber del Estado desarrollar políticas que garanticen a las víctimas de los delitos más graves que existen su derecho a la verdad, a la justicia y a la reparación. 
gobierno del Partido Popular de Mariano Rajoy, la Ley de Memoria Histórica carece de dotación presupuestaria para su aplicación.

En septiembre de 2008, el juez Baltasar Garzón ${ }^{13}$ impulsó estas denuncias asociativas donde se hacía expresa referencia a los nombres y apellidos de 130.000 desaparecidos del franquismo. El fiscal de la Audiencia Nacional alegó que los delitos de genocidio y crímenes de lesa humanidad no estaban tipificados en el Código Penal de 1932 que regía cuando se cometieron, y que no se podían aplicar con carácter retroactivo. El juez Garzón imputó al régimen franquista un delito de genocidio por estos y otros sucesos el 14 de octubre de 2008 , al ser delitos que no prescribían. ${ }^{14}$

A lo largo de 2009, diversas instancias de Naciones Unidas amonestaron al gobierno español e incluso le sugirieron la derogación de la Ley de Amnistía. En el apartado C, punto 9 del informe del Pacto Internacional de Derechos Civiles y Políticos, se señala lo siguiente:

El Estado parte debería: a) considerar la derogación de la Ley de amnistía de 1977 ; b) tomar las medidas legislativas necesarias para garantizar el reconocimiento de la imprescriptibilidad de los crímenes de lesa humanidad por los tribunales nacionales; c) prever la creación de una comisión de expertos independientes encargada de restablecer la verdad histórica sobre las violaciones de los derechos humanos cometidas durante la guerra civil y la dictadura; y d) permitir que las familias identifiquen y exhumen los cuerpos de las víctimas y, en su caso, indemnizarlas. (Naciones Unidas, 2009)

El gobierno español, dirigido entonces por el presidente socialista Rodríguez Zapatero, remitió al organismo internacional un informe que demostraba claramente cuál era el posicionamiento institucional del Estado español respecto a la impunidad. En los puntos 9 y 10 del informe emitido señalaba que:

(...) el Comité está descalificando una decisión respaldada por toda la sociedad española y que contribuyó a la transición a la democracia en España. La citada ley fue una demanda de toda la oposición democrática y fue una de las primeras leyes aprobadas por consenso por las mismas Cortes que aprobaron la Constitución de 1978. Además, no sólo la sociedad española sino también la

13 Juez de Instrucción número 5 de la Audiencia Nacional.

14 Garzón declaró extinguida la responsabilidad penal de los imputados ya fallecidos y remitió la causa a los juzgados territoriales. Poco después la Audiencia Nacional se inhibió ante una querella presentada en 2006 por crímenes contra la humanidad en España entre 1936 y 1951, a favor de numerosos juzgados provinciales. Todas las causas fueron archivadas y en las resoluciones de archivo se hizo mención expresa a la Ley de Amnistía. 
opinión pública mundial es conocedora y ha respaldado siempre el proceso de transición en España que fue posible, en parte, gracias a dicha Ley.

Y concluía indicando que el Comité de Naciones Unidas había

(...) cometido disfunciones procesales en términos de competencia (ausencia de referencia a la disposición pertinente del Pacto), proceso debido (ausencia de oportunidad de defensa en el procedimiento) y determinación de los hechos (desconocimiento del origen y significación social de la Ley de Amnistía). ${ }^{15}$

Unos meses más tarde sería el Comité contra la Tortura de Naciones Unidas quien, en el epígrafe "Ley de Amnistía e imprescriptibilidad de la tortura", apartado 21 del informe emitido, manifestaría que:

El Estado parte debería asegurar que los actos de tortura, que también incluyen las desapariciones forzadas, no sean crímenes sujetos a amnistía. Al respecto, el Comité alienta al Estado parte a continuar e incrementar sus esfuerzos para ayudar las familias de las víctimas a esclarecer la suerte de los desaparecidos, identificarlos y obtener las exhumaciones de sus restos, siempre que sea posible. Asimismo, el Comité reitera que, de acuerdo al Artículo 14 de la Convención, el Estado parte debe asegurar la reparación y el derecho a una indemnización a toda víctima de actos de tortura". Y concluía su informe marcando claramente el camino que debía recorrer el Gobierno: "El Estado parte debería asegurar la imprescriptibilidad de la tortura en todo caso (Naciones Unidas, 2009).

Acabó 2009 con un nuevo informe de Naciones Unidas donde se refería a la Ley de Amnistía. En esta ocasión fue el "Grupo de Trabajo sobre Desapariciones Forzosas de la ONU" el que denunció que no se habían investigado las desapariciones ocurridas durante la Guerra Civil española y el régimen de Franco, y que la infracción todavía pervivía pese a que la referida Ley declaró prescritos los delitos cometidos durante esos periodos históricos. Además, hizo referencia a que la Ley de Memoria Histórica española no contemplaba el delito de desaparición forzada y no ofrecía vía de recursos para las víctimas, vulnerando así su derecho a la verdad, la justicia y la reparación. ${ }^{16}$

Hubo en 2011 un intento de modificar la Ley de Amnistía en el Congreso de los Diputados. Fue una proposición de ley del Grupo Mixto que pretendía que los

15 Comentarios del Gobierno de España sobre las observaciones finales del Comité de Derechos Humanos. Examen de los informes presentados por los Estados Partes con arreglo al artículo 40 del pacto. España. Naciones Unidas, Pacto Internacional de Derechos Civiles y Políticos, 26 de enero de 2009.

16 Informe del Grupo de Trabajo sobre las Desapariciones Forzadas o Involuntarias. Asamblea General de Naciones Unidas, 21 de diciembre de 2009. 
crímenes del franquismo se pudieran investigar y juzgar. La iniciativa no salió adelante por el rechazo del PSOE, el PP y $\mathrm{CiU}^{17}$ (fue rechazada por 320 votos en contra, 8 a favor y 8 en contra).

En febrero de 2012, la Alta Comisionada de Naciones Unidas para los Derechos Humanos, Navi Pillay, solicitó la derogación de la Ley de Amnistía de 1977 al incumplir la normativa internacional en materia de derechos humanos. Se instaba a España a investigar las violaciones a los derechos humanos ocurridas en el pasado, incluidos los cometidos durante el régimen de Francisco Franco. El portavoz de la Alta Comisionada, Rupert Colville, también aseguró, en alusión al juez Baltasar Garzón, ${ }^{18}$ que: "los jueces no deberían ser enjuiciados por hacer su trabajo. En este caso, es la defensa de los estándares de las leyes internacionales de que la amnistía no debería ser concedida a responsables de crímenes contra la humanidad (ONU, 2012).

Desde 2013 han sido otras instancias de Naciones Unidas las que han señalado a las instituciones españolas que las amnistías, indultos y otras medidas similares que impiden que los autores de graves violaciones de los derechos humanos sean llevados ante los tribunales, son incompatibles con sus obligaciones internacionales. Nos referimos al Grupo de Trabajo sobre Desapariciones forzadas o involuntarias, al Comité contra la Tortura, al Comité de Derechos Humanos, al Comité contra la Desaparición Forzada y al Relator Especial sobre Verdad, Justicia y Reparación, entre otras, sin descartar la inestimable actividad de entidades sociales como Amnistía Internacional y Human Rights Watch.

Finalizando con este somero relato de las principales reprobaciones internacionales a la impunidad española en materia de derechos humanos, no debemos desdeñar el informe que el relator de la ONU, Pablo de Greiff, realizó en 2014 tras su amplia estancia en España. De Greiff incidió en que el Estado español debía dejar sin efecto la Ley de Amnistía pues se había utilizado para archivar prácticamente la totalidad de los casos que llegaban a los jueces. Consideró una necesidad que el gobierno español desarrollara "con urgencia" una política de Estado para reparar a las víctimas del franquismo, ya que el modelo de privatización de las exhumaciones existentes facilitaba la indiferencia de las instituciones del Estado. Por último, el informador de la ONU insistió al gobierno en la anulación de todas las sentencias de los consejos sumarísimos, reivindicación de las víctimas que se descartó durante el

17 Convergencia i Unió.

18 Garzón acababa de ser inhabilitado como juez por 11 años por el Tribunal Supremo español, siendo expulsado de la carrera judicial por ordenar escuchas telefónicas en la investigación de la trama de corrupción Gürtel. 
debate sobre de la Ley de Memoria Histórica por el temor a que los afectados reclamaran indemnizaciones. ${ }^{19}$

Por último, el 20 de diciembre de 2016, la Comisión de Justicia del Congreso de los Diputados rechazó, con 26 votos en contra, 10 a favor y una abstención, una proposición no de Ley que instaba a la modificación de la Ley de Amnistía para establecer que no se aplicaría a casos de torturas o desapariciones forzadas, ni a los crímenes de genocidio o de lesa humanidad, tal y como dispone la normativa internacional.

\section{España y su asignatura pendiente: con impunidad no hay reconciliación ni consolidación democrática}

En parte como consecuencia de la singular transición española, la normativa internacional generada en materia de protección de los derechos humanos y de persecución y sanción de los crímenes contra la humanidad evolucionó sustancialmente. La denominada justicia transicional trascendió el valor descriptivo y explicativo característicos de la segunda postguerra mundial para conformar un conjunto de normas que impuso a los Estados y a la comunidad internacional ciertas obligaciones a la hora de enfrentar legados de violaciones sistemáticas de los derechos humanos en escenarios de transición de periodos bélicos a la paz o de regímenes de dictadura a la democracia (Méndez, 2013).

Estas obligaciones tienen su centro en una nueva consideración de las víctimas, que han pasado a ocupar un lugar central en los procesos de justicia transicional y reconstructiva, coincidiendo con un concepto de justicia que ha sido definida como anamnética, y que reconoce la vigencia de toda injusticia sufrida en el pasado hasta que los derechos de las víctimas se vean restaurados (Zamora y Mate, 2011). Este esquema de justicia transicional se aplicó tras el colapso de la Unión Soviética y los procesos simultáneos de democratización en Europa del Este, África y Latinoamérica, con la desaparición de las dictaduras existentes y la desmovilización de guerrillas apoyadas en mayor o menor medida por el bloque comunista. La oleada de transiciones políticas se inició con la liberalización vivida en los países del Cono Sur americano a finales de los setenta y comienzos de los ochenta; continuó con la emergencia de las antiguas repúblicas satélite de Europa del Este y finalizó con los procesos de paz de Nicaragua (1988), El Salvador (1992) y Guatemala (1996) (Moreno, 2018), alcanzando su punto álgido en el proceso de paz que vive en la actualidad Colombia.

19 Informe del Relator Especial sobre la promoción de la verdad, la justicia, la reparación y las garantías de no repetición, Pablo de Greiff. Asamblea General de Naciones Unidas, 22 de julio de 2014. 


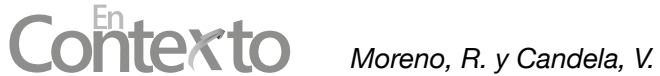

Para esta etapa, la Justicia Transicional adoptó como función principal, según Teitel (2003), la reconstrucción nacional en el marco de un discurso que enfatizó las virtudes de la democracia y el Estado de Derecho. De ahí que la discusión se centró en la manera en que los nuevos gobiernos democráticos debían restaurar la paz nacional, someter a los culpables de crímenes durante los regímenes anteriores y avanzar en la construcción de una sociedad incluyente y libre de violaciones a los Derechos Humanos (pp.69-94). El caso argentino en su etapa inicial, por ejemplo, reveló la imposibilidad de realizar enjuiciamientos al estilo de Núremberg, aunque demostró que el Derecho Internacional puede constituirse en una fuente alternativa al Estado de Derecho para guiar los juicios nacionales en una sociedad en transición (Rodríguez, 2011).

Los procesos latinoamericanos plantearon en este sentido cuestiones cruciales en términos de tensión entre paz, verdad y justicia, sacando a la luz dilemas del tipo "justicia versus impunidad" u "olvido versus memoria", entre otros. La justicia transicional se sitúa así entre el deber de memoria con las víctimas y el derecho a ciertos olvidos a favor de los intereses nacionales; de tal manera que "mucha" memoria puede contribuir a la lucha contra la impunidad, pero en ocasiones deviene en problemas para la transición. Pero, también, "mucho" olvido frena o hace imposible la justicia y la verdad para una nación. Es por ello que algunos actores del tránsito piden insistentemente el cierre de pasados violentos, en aras de conseguir la reconciliación nacional (Orozco, 2009).

En esa diatriba se sigue encontrando actualmente la sociedad española, cuarenta y tres años después de la muerte del dictador. Así las cosas, podemos afirmar que sin justicia ni reparación es difícil alcanzar la reconciliación. Ésta solo puede conseguirse tras completar un ciclo reparador integrado por el conocimiento de la verdad y la aplicación de la justicia en favor de las víctimas, que incluye la reparación, la rehabilitación y medidas de no repetición. Solo al final de ese ciclo puede existir el perdón y el reencuentro de la sociedad. En definitiva, no puede existir superación del pasado ni reconciliación sin derecho penal. Por ello nos encontramos en la España actual una sociedad fracturada y enfrentada; dos mitades que viven realidades distintas, con representantes que reproducen en la competencia política las fuerzas que pelearon en la guerra. Queda mucho por hacer para conseguir esa reconciliación, a pesar de lo ya recorrido. La Ley de Memoria Histórica es un ejemplo: la ley reconoce y amplía derechos y establece medidas a favor de quienes padecieron persecución o violencia durante la Guerra Civil y la dictadura, pero como hemos visto presenta muchas lagunas y defectos. 
El papel del gobierno central a veces es suplido por otras administraciones o por iniciativas populares. Algunas comunidades autónomas, antes incluso de la aprobación de la Ley de Memoria Histórica, han impulsado todo tipo de iniciativas para rehabilitar a las personas que vieron menoscabados sus derechos durante la Guerra Civil y la represión política posterior, como ocurre sobre todo en Cataluña, País Vasco ${ }^{20}$ y Andalucía. ${ }^{21}$ Desde los años 80, las universidades también participan en la recuperación de la memoria histórica y la participación ciudadana está siendo clave en este proceso. La principal entidad es la Asociación para la Recuperación de la Memoria Histórica, que desde el año 2000 ha llevado a cabo más de 150 excavaciones de fosas comunes logrando identificar a más de mil víctimas de la represión durante la Guerra Civil.

\section{Referencias}

Boletín Oficial del Estado núm. 243, de 10 de octubre de 1979.

Boletín Oficial del Estado núm. 126, de 27 de mayo de 2002.

Casanova, J., "Desaparecidos”. En El País, 10 de julio de 2008.

Decreto del Departamento de Justicia y Administración Pública 107/2012, de 12 de junio, de declaración y reparación de las víctimas de sufrimientos injustos como consecuencia de la vulneración de sus derechos humanos, producida entre los años 1960 y 1978 en el contexto de la violencia de motivación política vivida en la Comunidad Autónoma del País Vasco.

Fonseret, R. y Candela, V.

Espinosa Maestre, Francisco (2007). "De saturaciones y olvidos. Reflexiones en torno a un pasado que no puede pasar". En Hispania Nova, Revista de Historia Contemporánea, $\mathrm{n}^{\circ} 7, \mathrm{p} .25$.

Informe del Grupo de Trabajo sobre las Desapariciones Forzadas o Involuntarias. Asamblea General de Naciones Unidas, 21 de diciembre de 2009.

Informe del Relator Especial sobre la promoción de la verdad, la justicia, la reparación y las garantías de no repetición, Pablo de Greiff. Asamblea General de Naciones Unidas, 22 de julio de 2014.

20 Decreto del Departamento de Justicia y Administración Pública 107/2012, de 12 de junio, de declaración y reparación de las víctimas de sufrimientos injustos como consecuencia de la vulneración de sus derechos humanos, producida entre los años 1960 y 1978 en el contexto de la violencia de motivación política vivida en la Comunidad Autónoma del País Vasco. BOPV 19-VI-2012.

21 Ley de Memoria Democrática de Andalucía, 2017. 


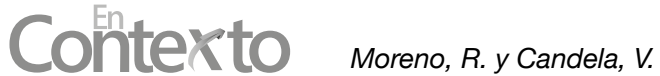

Juliá, Santos (2008). "Presencia de la guerra y combate por la amnistía en la transición a la democracia". En Beramendi, J.; Baz, María Jesús (Eds.), Identidades y memorias imaginadas. Valencia: Universitat de València, p. 102.

Ley 46/1977, de 15 de octubre, de Amnistía.

Ley 52/2007, de 26 de diciembre, por la que se reconocen y amplían derechos y se establecen medidas en favor de quienes padecieron persecución o violencia durante la guerra civil y la dictadura.

Ley de Memoria Democrática de Andalucía 14/3/2017.

Méndez, Juan E. (2013). "Justicia de Transición". En Escudero Alday, Rafael y Pérez González, Carmen (eds.), Desapariciones forzadas, represión política y crimenes del franquismo. Madrid: Trotta, pp. 13-30.

Moreno Fonseret, R. (2018). "Verdad e impunidad en Centroamérica". En Moreno Fonseret, R. y Payá López, P., Memoria y Justicia Transicional en Europa y América Latina. Granada: Comares, pp. 175-203.

Orozco, I. (2009). Justicia transicional en tiempos del deber de memoria. Bogotá: Temis-Universidad de los Andes.

Pacto Internacional de Derechos Civiles y Políticos, 5 de enero de 2009.

Pacto Internacional de Derechos Civiles y Políticos, 26 de enero de 2009.

Preston, P. (2011). El Holocausto español. Odio y exterminio en la guerra civil $y$ después. Madrid: Debate.

Reig Tapia, Alberto (1984). Ideología e historia. Sobre la represión franquista y la guerra civil. Madrid: Akal,

Richards, M. (2007). "The limits of quantification: Francoist repression and historical methodology". En Hispania Nova. Revista de Historia Contemporánea, $\mathrm{n}^{\circ} 7$.

Rodríguez Montenegro, P. "Los límites del perdón. Notas sobre la justicia transicional en Sudáfrica, Centroamérica y Colombia". En Justicia Juris, Vol. 7, nº 2, pp. 52-53. 2011.

Sánchez Recio, G. (2012). "Debate sobre la naturaleza de la represión en España". En Hispania Nova, Revista de Historia Contemporánea, no 10. 
3/4: (2016). Operación quirúrgica en el cuerpo social. La represión política en Monovar. Alicante: Universidad de Alicante.

3/4: (2016) y Moreno Fonseret, R. (ed.). Aniquilación de la República y castigo a la lealtad, Alicante: Universidad de Alicante.

3/4: (2018). Afrontar el pasado. El debate político sobre la violencia de la guerra civil y la represión franquista en la democracia española. En Moreno Fonseret, R. y Payá López, P., (eds.), Memoria y Justicia Transicional en Europa y América Latina. Granada: Comares.

Teitel, R.G. (2003). “Transitional Justice Genealogy”. En Harvard Human Rights Journal, Vol. 16, pp. 69-94. Artículo traducido al castellano por el Centro de Derechos Humanos, Facultad de Derecho Universidad de Chile.

Zamora, José A. y Mate, Reyes (eds.) (2011). Justicia y memoria. Hacia una teoría de la justicia anamnética. Barcelona: Anthropos.

\section{Para citar este artículo:}

Moreno, R. y Candela, V. (2017). Imprescriptibilidad vs impunidad en la transición española. En-Contexto, 6(9), 233-249. 